The authors respond: We thank you for your kind words and your appreciation of our study. First of all, however, let's clarify the fact that we never claimed that 'direct wax' onlays have better longevity than indirect ones. In fact that hypothesis was not tested. Our study demonstrated that 'direct wax' onlays have a comparable longevity to previously reported indirect restorations and that this method is viable under a general dental practice environment.

Now, considering your question about Figure 1c, indeed LL7 was an inlay and consequently not included in our study; LL8 on the other hand was an MO onlay: due to its partial nature, the distal cusps have been covered, but not the mesial ones (and this might possibly be the reason for their worse survival compared to the full MOD onlays).

As far as the fracture criterion is concerned, onlays do not really fracture, with exception maybe of a very thin isthmus; this option was included for the sake of completeness. Moreover, perforations have been included into this category.

Finally, concerning your interesting comment of non vital teeth endodontic outcome. Strictly speaking, any restorative procedure on a root treated tooth may cause microleakage and hence endodontic failure. Now, how likely this is to happen, there is no evidence. In our opinion reasons intrinsic to the endodontic procedures are more likely to cause failure, but the aforementioned case cannot be ruled out.

DOI: 10.1038/sj.bdj.2009.1017

\section{DISINGENUOUS VIEWS}

Sir, I read with some interest the reply to my letter Another hiccup (BDJ 2009; 206: 509) by I. Brook and C. Freeman. My letter drew attention to an anomaly of registration that has led to a perceived unfairness to dual qualified consultant oral and maxillofacial surgeons registered with the General Medical Council (GMC) and the General Dental Council (GDC). It was with some regret and disappointment that I note the statements contained within this letter.

Statements published by the GDC, ${ }^{1}$ the British Association of Oral and Maxillofacial Surgeons ${ }^{2}$ (BAOMS) and the Postgraduate Medical Education and
Training Board ${ }^{3}$ (PMETB) all define very clearly that the scope of work outlined by I. Brook and C. Freeman is well within that defined to be the remit of oral and maxillofacial surgery consultants.

I was also dismayed that the authors have sought to extend my personal views on an anomaly for temporary registered dentists to that of an advisory matter from BAOMS. The latter has in no way advised any of its fellows with regards to whether they should be registered with the GDC and have merely outlined the new GDC rules of registration.

Oral and maxillofacial surgery is now a medical specialty and I direct the authors I. Brook and C. Freeman to any of the references listed below, which are and have been readily available within the public domain. The scenario they present does not present any difficulties with regards to the defined remit of practice by a dually qualified, singly registered consultant oral and maxillofacial surgeon and the publication of such disingenuous views does not help what has been a difficult situation to address.

S. Laverick By email

1. General Dental Council. Practice of dentistry statement. www.gdc-uk.org/NR/rdonlyres/563578AC10D2-4A8B-A3FF-6B029F5E772E/76102/ Practiceofdentistrystatement.doc (accessed 2 November 2009).

2. British Association of Oral and Maxillofacial Surgeons. BAOMS position statement: The practice of oral and maxillofacial surgery (OMFS) by non-GDC medical registrants. http://www.baoms.org.uk/ downloaddoc. asp? $i d=212$ (accessed 2 November 2009).

3. Intercollegiate Surgical Curriculum Programme. Oral and maxillofacial surgery syllabus webpages. https://www.iscp.ac.uk/Syllabus/Overview.aspx?e $n c=1 k C 9 R 8 V 0 U h q Y w U J W L f 7$ USFGHkUwSFKIosHep $\mathrm{YhBHhXO}=$ (accessed 2 November 2009).

\section{DOI: 10.1038/sj.bdj.2009.1018}

\section{UNDERPINNED BY EXPERIENCE}

Sir, I write regarding the news story titled New professor appointed (BDJ 2009; 207: 150). As Head of the School of Dentistry at the University of Central Lancashire I wish to inform colleagues that I was not involved in this appointment as it is in the Institute of Postgraduate Dental Education that is not part of the new graduate entry dental school. My personal view on academic appointments has not changed since I published the article Science, myths and lies in dentistry (BDJ 1991; 171: 74). In those days I was an angry young man, now I am a grumpy old man; but I still believe that the award of academic titles should be underpinned by traditional academic training and experience.

L. Mair

Preston

DOI: 10.1038/sj.bdj.2009.1019

\section{USE OF HOISTS}

Sir, I am writing to you in response to the article Obesity and dentistry: a growing problem (BDJ 2009; 207: 171-175). I would like to add a few points.

It would be pertinent to mention about the use of hoists. When I attended the induction programme for my first job as a community dentist, I was introduced to the use of hoists for lifting bariatric patients. These hoists are available in different makes and sizes and each has a recommended maximum load it can lift. In surgery I have used the hoist a few times to transfer patients from wheelchair to dental chair.

We also have a very wide wheelchair designed for bariatric patients and we use a wheelchair tipper which again is indispensable for such patients.

These patients are also a high risk category for treatment under general anaesthesia. One of my bariatric patients went into cardiac arrest on the operation table when she had to undergo full clearance under GA. She had to undergo a defibrillator to start her heart again and the operation had to be abandoned.

Z. Imran

Dundee

DOI: 10.1038/sj.bdj.2009.1020

\section{ODD PRACTICE}

Sir, in the online edition of the $B D J$, Khosropanah et al. report (BDJ 2009; 207: E8) the results of an unusually designed study which assessed the efficacy of panoramic radiographs to detect carotid artery calcifications by determining the level of agreement between the radiographs and Doppler sonography (DS). ${ }^{1}$ The study design is odd and a reverse of usual clinical dental practice in that they referred for radiographs patients who had already had a physician obtained DS study. The authors determined that the level of agreement between the two imaging sys- 